\section{Characterization of Dentifrices Containing Desensitizing Agents, Triclosan or Whitening Agents: EDX and SEM Analysis}

Shelon Cristina Souza Pinto ${ }^{1}$, Sérgio Paulo Hilgenberg ${ }^{1}$, Denise Stadler Wambier ${ }^{1}$, Paulo Vitor Farago ${ }^{1}$, Matheus Coelho Bandéca², Fábio André Santos ${ }^{1}$
'Department of Dentistry, School of Dentistry, UEPG - Ponta Grossa State University, Ponta Grossa, PR, Brazil ${ }^{2}$ Department of Post-

Graduation, School of Dentistry, UniCEUMA - CEUMA University, São Luis, MA, Brazil

Correspondence: Profa. Dra. Shelon Cristina Souza Pinto, Avenida General Carlos Cavalcanti, 4748, 84030-900 Ponta Grossa, PR, Brasil. Tel: +55-42-9924-4198. e-mail: shelonsouzap@gmail.com
Dentifrices with different compositions are available on the market, but there is limited information about their properties. The aim of this in vitro study was to evaluate the physicochemical characteristics of 12 dentifrices divided into three categories, as containing desensitizing agents, Triclosan or whitening agents. Desiccation loss/residue analysis: $5 \mathrm{~g}$ of dentifrice was weighed five times for each group. $\mathrm{pH}$ analysis: $5 \mathrm{~g}$ of dentifrice were diluted in three parts of distilled water and analyzed using a digital potentiometer. Scanning electron microscopy (SEM): analysis of ashes, shape and size of the particles. Energy-dispersive $x$-ray spectroscopy (EDX): identification of the abrasive elements. Data were analyzed using ANOVA, Bonferroni post hoc test ( $\alpha=0.05$ ). Desiccation loss: $38.21 \%$ to $65.83 \%$. Dentifrices containing Triclosan and desensitizing agents showed statistically significant differences among them $(p<0.05)$. Whitening dentifrices showed statistically significant differences between Close-Up Whitening and Sensodyne Branqueador (44.72\%, $65.83 \%$, respectively). Most dentifrices presented neutral or basic $\mathrm{pH}$. Different shape and size particles were observed in the SEM analysis. Abrasive elements were identified in the EDX. These results demonstrate that the evaluated dentifrices had different properties and their composition influences directly their characteristics, thus resulting in a more or less abrasive action on tooth surface. Knowing the characteristics of the dentifrices is important to indicate the ideal product for each case.
Key Words: dentifrices, triclosan, $\mathrm{pH}$.

\section{Introduction}

The decrease in the prevalence of caries disease is certainly due to the use of fluoride by most of the population worldwide. Dentifrices are the greatest source of fluorides. These agents are regularly used and the formulation of dentifrices has been improved to enhance their therapeutic properties by incorporating agents such as triclosan, potassium nitrate, strontium chloride and different abrasive substances $(1,2)$.

In order to ensure their effectiveness, dentifrices must have ideal physicochemical characteristics. To remove supragingival biofilm, toothbrushing causes disarrangement in the intermicrobial matrix. To remove the pigmentation from the enamel surface, dentifrice composition requires abrasives (2).

The abrasiveness control of dentifrices is an important factor to be considered because dental staining varies among the population and the continuous use of dentifrices may cause problems like abrasion of tooth structure and gingival recession $(1,3)$. The use of dentifrices with high concentration of abrasive agents after the consumption of acid beverages may increase enamel and dentine abrasion (4). Different abrasive agents, detergents or a combination of formulations produce different sources of abrasion (5). According to Worschech (6), the roughness of the dental enamel may be increased by the continuous use of abrasive dentifrices during at home bleaching therapy.

The ideal dentifrice promotes the cleaning of the dental surface with minimum abrasion, without causing irritating effects on oral mucosa (7). As shown by Kielbassa (8), in addition to its abrasive potential, the acidity of dentifrice may increase significantly enamel and dentin erosion. Therefore, it is also necessary to know the $\mathrm{pH}$ of dentifrices in order to know their abrasive potential and acidity.

The goal of this study was to evaluate physicochemical characteristics of 12 dentifrices divided into three categories: desensitizing dentifrices, triclosan-containing dentifrices and whitening dentifrices. The null hypothesis is that the tested dentifrices present no differences in the evaluated characteristics.

\section{Material and Methods}

Considering their physicochemical characteristics and differences in the properties, 12 dentifrices of different brands, belonging to one of the following categories were used: desensitizing dentifrices, triclosan-containing 
dentifrices and whitening (Table 1).

The dentifrices were submitted to the tests of desiccation loss and residue analysis; analysis of abrasive agents by scanning electron microscopy (SEM); energydispersive x-ray spectroscopy (EDX); granulometry; and $\mathrm{pH}$ analysis. For such purpose, 5 samples were used for each dentifrice.

\section{Desiccation Loss and Residue Analysis}

The dentifrice was weighed on a Petri dish $(5.0 \mathrm{~g})$. This procedure was repeated five times for each group. After being weighed, the samples were heated in an oven at 105 ${ }^{\circ} \mathrm{C}$ for $24 \mathrm{~h}$. They were then weighed again, repeating this process until the same weight was recorded in consecutive checks. Loss by desiccation was calculated from the difference between the initial and final weights.

\section{pH Analysis}

The $\mathrm{pH}$ was measured using a previously calibrated digital potentiometer (DMPH-2; Digimed, São Paulo, SP, Brazil). Measurements were performed only once for each one of the five samples at a dilution of $5.0 \mathrm{~g}$ suspended in three parts of distilled water $(15 \mathrm{~mL})$.$$
\text { p }
$$
ashes, which were analyzed with a SEM microscope (Shimadzu SSX 550; Shimadzu do Brasil, São Paulo, SP, Brazil), operated at $15 \mathrm{kV}$ and $1000 \times$ magnification. EDX

Table 1. Main agents presents in composition of the dentifrices evaluated

\begin{tabular}{|c|c|c|c|c|c|c|}
\hline Groups & Trademark & Manufacturer & $\begin{array}{c}\text { Fluoride } \\
\text { (ppm) }\end{array}$ & Bleaching agent & Desensitizing agent & Triclosan \\
\hline \multirow{4}{*}{$\begin{array}{l}\text { Dentifrices } \\
\text { containing } \\
\text { desensitizing } \\
\text { agents }\end{array}$} & Colgate Sensitive & Colgate-Palmolive & 1500 & & $5 \%$ potassium citrate & - \\
\hline & Sensodyne Original & GlaxoSmithKline & 1490 & & $10 \%$ strontium chloride & - \\
\hline & Sensodyne Bicarbonato de Sódio & GlaxoSmithKline & & & $5 \%$ potassium nitrate & - \\
\hline & Sensodyne - Cool Gel & GlaxoSmithKline & 1100 & & $5 \%$ potassium nitrate & - \\
\hline \multirow{4}{*}{$\begin{array}{l}\text { Triclosan- } \\
\text { containing } \\
\text { dentifrices }\end{array}$} & Colgate Total 12 & Colgate-Palmolive & 1450 & & & + \\
\hline & Sensodyne Proteção Total & GlaxoSmithKline & 1400 & & & + \\
\hline & Close-Up Gel & Unilever & 1500 & & & + \\
\hline & Prevent Anti-Placa & Colgate-Palmolive & & & & + \\
\hline \multirow{4}{*}{$\begin{array}{l}\text { Dentifrices } \\
\text { containing } \\
\text { whitening agents }\end{array}$} & Close-Up Whitening & Unilever & 1500 & Perlite & & - \\
\hline & Sorriso Branqueador & Colgate-Palmolive & 1500 & Alumina & & - \\
\hline & Sensodyne Branqueador & GlaxoSmithKline & 1500 & Amorphous silica & & - \\
\hline & Colgate Sensitive Branqueador & Colgate-Palmolive & 1450 & Hidrous silica & & - \\
\hline
\end{tabular}

microanalysis (Shimadzu SSX 550; Shimadzu do Brasil) was performed to determine the presence of particular chemical elements in the dentifrices. The spectrum was obtained at 15

\section{Statistical Analysis}

The data were analyzed by one-way ANOVA with Bonferroni post hoc test $(\alpha=0.05)$. All data were analyzed with PASW Statistics (version 18; SPSS Inc., Chicago, IL, USA).

\section{Results}

\section{Desiccation Loss and Residue Analysis}

Dentifrices Containing Desensitizing Agents: there were statistically significant differences $(p<0.05)$, except between Sensodyne Original (SO) and Sensodyne Cool Gel. For this group, Sensodyne Original and Sensodyne Cool Gel showed larger amount of solid residues $(64.07 \%$ and $60.85 \%$, respectively, Table 2).

Triclosan-Containing Dentifrices: there were statistically significant differences $(p<0.05)$, except between Sensodyne Total Protection and Close-Up Gel. For this group, Prevent and Sensodyne Total Protection have shown larger amount of solid residues (55.16\% and 40.92\%, respectively, Table 2). Dentifrices Containing Whitening Agents: there were statistically significant differences between Close-Up Whitening and Sensodyne Branqueador (44.72\% and $65.83 \%$, respectively); Sorriso Branqueador and Sensodyne Branqueador (39.90\% and 65.83\%, respectively); Sensodyne Branqueador and Colgate Sensitive Branqueador (65.83\% 
and $40.07 \%$, respectively).

Multiple comparisons showed that there were statistically significant differences for almost all tested dentifrices (Table 2). Sensodyne Branqueador dentifrice (Group 3) showed larger amount of solid residue (65.83\%).

\section{pH Analysis}

Dentifrices $\mathrm{pH}$ are shown in Table 3. There were statistically significant differences $(p<0.05)$ among groups (Table 3). Most dentifrices presented neutral or basic $\mathrm{pH}$, except Prevent Anti-Placa and Sensodyne Cool Gel dentifrices (Group $1-6.37 \pm 0.046$ and Group $2-\mathrm{pH} 6.33$ \pm 0.066 , respectively).

\section{SEM and EDX Analyses}

Dentifrices Containing Desensitizing Agents (Fig. 1)

Colgate Sensitive: SEM micrographs showed spherical and rounded particles. Some particles were joined and arranged in conglomerates, but not sharp. Particle shape showed less abrasive characteristics.

Sensodyne Bicarbonato de Sódio [Sodium Bicarbonate]: Several clusters of small spherical particles could be observed. Some SEM micrographs revealed particles that

Table 2. Results for desiccation loss and residue analysis of the dentifrices

\begin{tabular}{ll}
\hline Groups and dentifrices $\quad$ Mean percent values \\
\hline
\end{tabular}

Dentifrices containing desensitizing agents

$\begin{array}{ll}\text { Colgate Sensitive } & 41.82 \% \text { A } \\ \text { Sensodyne Original } & 64.07 \% \text { B } \\ \text { Sensodyne Bicarbonato de Sódio } & 51.40 \% \quad \text { C } \\ \text { Sensodyne Cool Gel } & 60.85 \% \text { D }\end{array}$

Triclosan-containing dentifrices

$\begin{array}{ll}\text { Colgate Total } 12 & 46.99 \% \text { A } \\ \text { Sensodyne Proteção Total } & 40.92 \% \text { B } \\ \text { Close-Up Gel } & 38.21 \% \text { C } \\ \text { Prevent Anti-Placa } & 55.16 \% \text { D }\end{array}$

Dentifrices containing whitening agents

$\begin{array}{ll}\text { Close-Up Whitening } & 44.72 \% \text { A } \\ \text { Sorriso Branqueador } & 39.90 \% \text { B } \\ \text { Sensodyne Branqueador } & 65.83 \% \text { C } \\ \text { Colgate Sensitive Branqueador } & 40.07 \% \text { A }\end{array}$

Different letters indicate statistically significant differences between groups ( $p<0.05$, ANOVA and post-test Bonferroni). seemed to be dentifrice chips, which may have occurred because the dentifrice in these samples was not entirely in the ash form.

Sensodyne Cool Gel: It presented some small and spherical particles and some large rhomboid and pointed particles, which may indicate signs of greater abrasiveness.

Sensodyne Original: Smaller and spherical particles, which may represent a minor abrasion.

Triclosan-Containing Dentifrices (Fig. 2)

Sensodyne Total Protection: SEM micrographs did not show any particles.

Close Up Gel: Large and irregular particles, which may indicate signs of greater abrasiveness.

Colgate Total 12: Small, rounded and irregular particles, which may indicate some abrasiveness.

Prevent Antiplaque: Small, spherical and regular particles, which may indicate little abrasiveness.

Dentifrices Containing Whitening Agents (Fig. 3)

Close Up Whitening: Large and irregular particles, which may indicate greater abrasiveness.

Colgate Sensitive Whitening: Small and medium-sized

Table 3. Results for $\mathrm{pH}$ of the dentifrices

Dentifrices Mean \pm standard deviation

Dentifrices containing desensitizing agents

$\begin{array}{ll}\text { Colgate Sensitive } & 7.21 \pm 0.013 \mathrm{~A} \\ \text { Sensodyne Original } & 7.81 \pm 0.011 \mathrm{D} \\ \text { Sensodyne Bicarbonato de Sódio } & 8.70 \pm 0.057 \mathrm{~B} \\ \text { Sensodyne Original } & 7.81 \pm 0.011 \mathrm{D}\end{array}$

Triclosan-containing dentifrices

$\begin{array}{ll}\text { Colgate Total } 12 & 7.76 \pm 0.029 \text { C } \\ \text { Sensodyne Proteção Total } & 8.36 \pm 0.055 \text { A } \\ \text { Close-Up Gel } & 7.15 \pm 0.040 \text { B } \\ \text { Prevent Anti-Placa } & 6.33 \pm 0.066 \text { D }\end{array}$

Dentifrices containing whitening agents

$$
\begin{array}{lc}
\text { Close-Up Whitening } & 7.87 \pm 0.079 \text { A } \\
\text { Sorriso Branqueador } & 10.09 \pm 0.142 \mathrm{~B} \\
\text { Sensodyne Branqueador } & 9.11 \pm 0.155 \mathrm{C} \\
\text { Colgate Sensitive Branqueador } & 8.00 \pm 0.043 \mathrm{~A}
\end{array}
$$

Different letters indicate statistically significant differences between dentifrices ( $p<0.05$, ANOVA and post-test Bonferroni). 

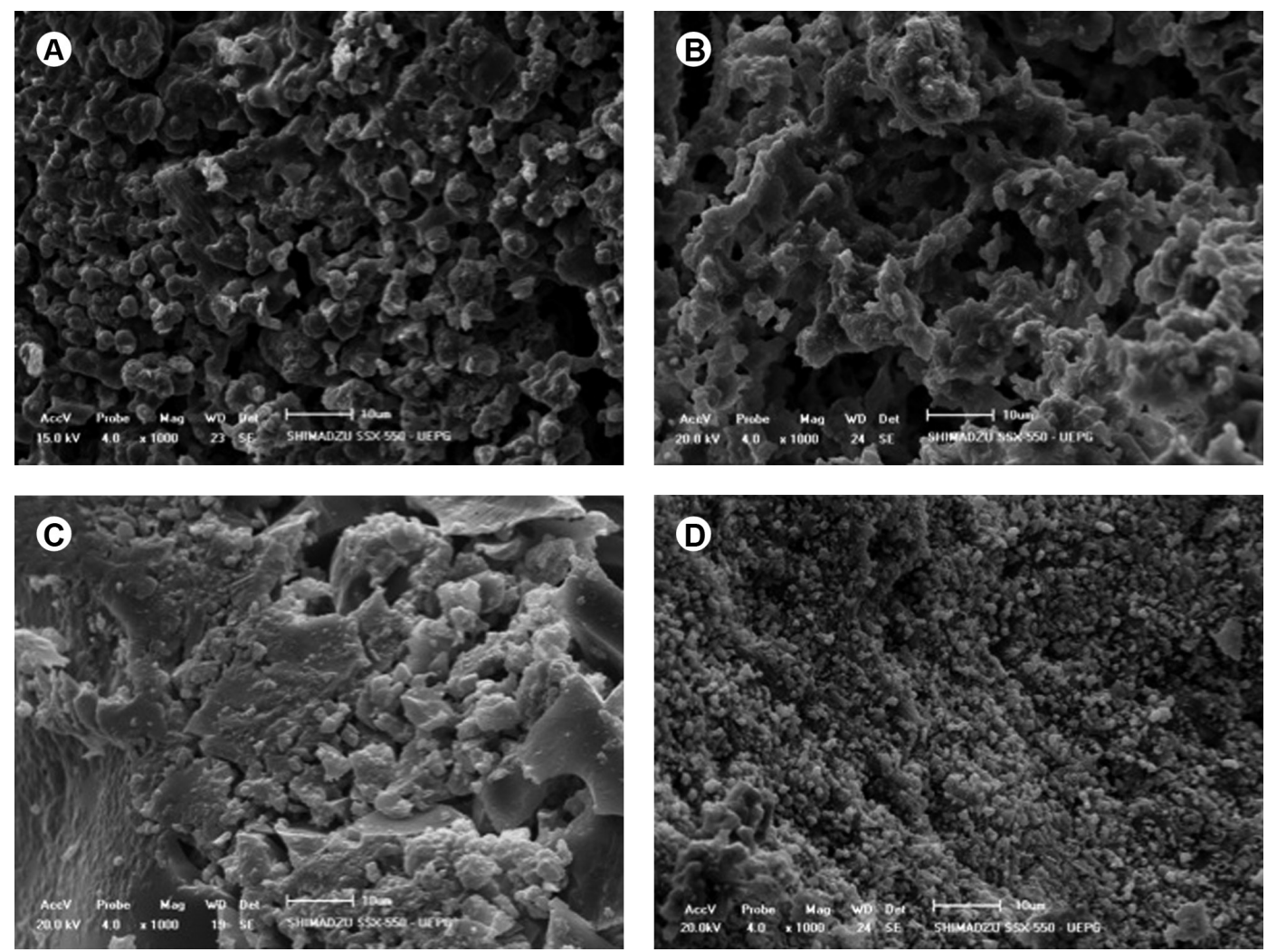

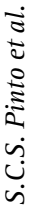

Figure 1. Dentifrices containing desensitizing agents: SEM micrographs of inorganic particles. A: Colgate Sensitive; B: Sensodyne Bicarbonato de Sódio; C: Sensodyne Cool Gel; D: Sensodyne Original.
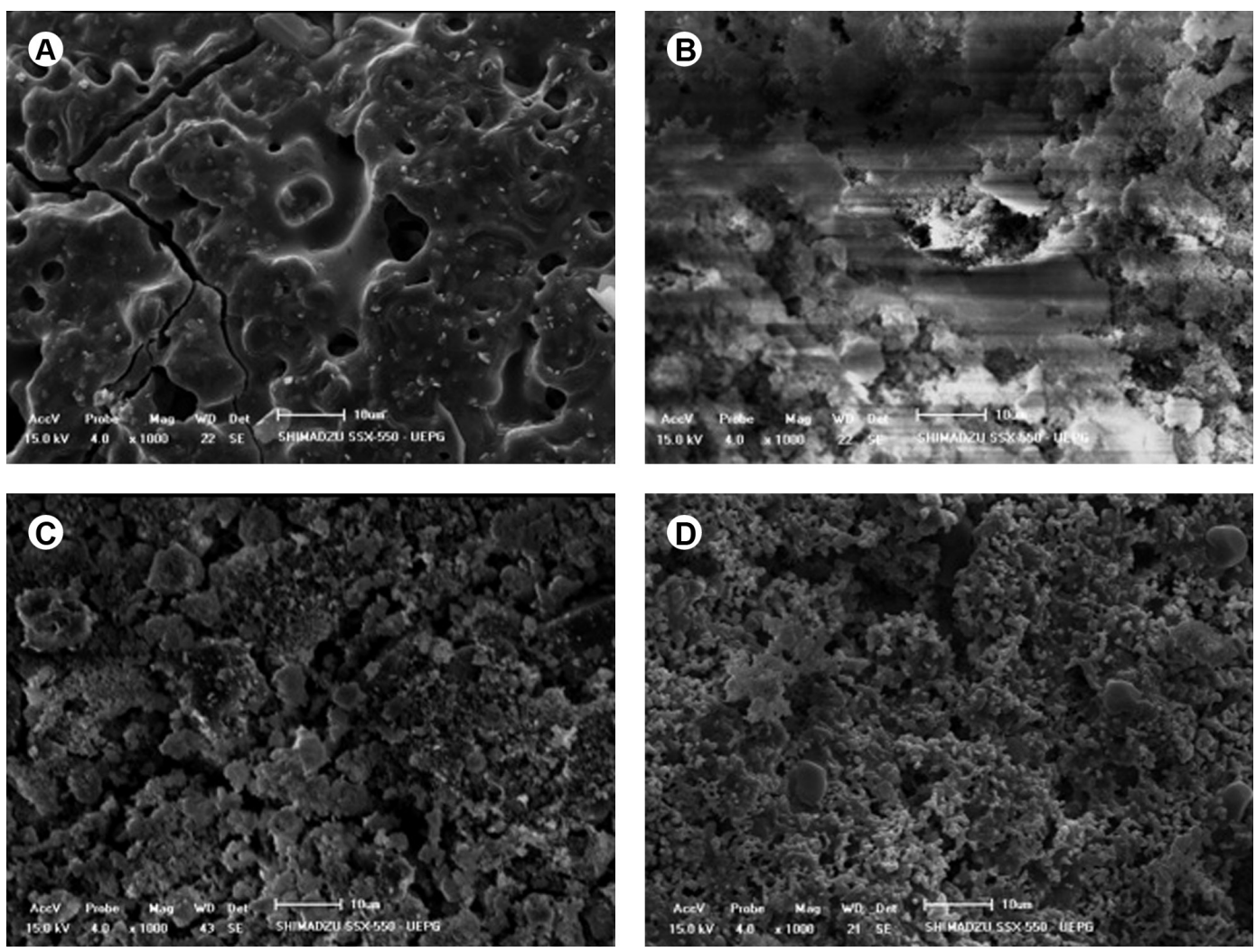

Figure 2. Triclosan-containing dentifrices: SEM micrographs of inorganic particles. A: Sensodyne Proteção Total; B: Close-Up Gel; C: Colgate Total 12; D: Prevent Anti-Placa. 
particles that are rather regular than irregular, which may indicate minor abrasion.

Sensodyne Whitening: Small and regular particles, which may indicate little abrasiveness.

Sorriso Whitening: Small, spherical and regular particles, which may indicate little abrasiveness.

The EDX analysis showed the elements present in the abrasive agent of each product. Dentifrices containing calcium carbonate as abrasive agent presented calcium (Ca) and carbon $\mathrm{C}$. Dentifrices containing silica as abrasive agent showed silicon (Si) and oxygen (0) in the EDX analysis.

\section{Discussion}

Dentifrices must be sufficiently abrasive to perform their functions without causing damage to the teeth and must provide maximum cleaning with minimum wear. However, tooth structure loss may occur in the crown, the root or in both, forming non-carious cervical lesions. Studies on non-carious cervical lesions have reported that risk factors for tooth abrasion include age, oral hygiene and dentifrice $(3,9)$.

Dentifrices are used daily by the population worldwide, but little information is available about these products, which would be important for dentists to recommend the proper use to patients.

The $\mathrm{pH}$ of the dentifrices analyzed in this study was neutral and basic, except for Sensodyne Cool Gel (Group 1) and Prevent Antiplaca (Group 2), which presented a slightly acidic $\mathrm{pH}$. A concern regarding the use of acidic products is the possibility of increasing enamel wear due to the synergistic action of erosion and abrasion during tooth brushing (10). The alkaline $\mathrm{pH}$ of dentifrices helps neutralizing acid biofilm, which can cause dental caries (11). Some authors have reported that dentifrices with acidic $\mathrm{pH}$ increase the binding of fluoride to the teeth $(12,13)$. A recent in vitro study showed that a 550- $\mu \mathrm{g} \mathrm{F/g} \mathrm{acidified}$ dentifrice ( $\mathrm{pH}$ 5.5) had the same effectiveness as a 1.100- $\mu \mathrm{g}$ $\mathrm{F} / \mathrm{g}$ neutral dentifrice in a $\mathrm{pH}$-cycling model (7). Using the same protocol, Alves et al. (10) found that dentifrices with a lower $\mathrm{pH}$ (4.5) led to better results when compared with those reported by Brighenti et al. (7). These data suggest that the $\mathrm{pH}$ reduction leads to less mineral loss, probably because of the formation of more $\mathrm{CaF}_{2}$ adsorbed to the enamel surface (and therefore greater availability of F). It is important to observe that the tested dentifrices had slightly acidic $\mathrm{pH}$, which may have little influence on the fluoride action on the enamel surface. Johannsen et al. (14) carried out measurements of the $\mathrm{pH}$ of dentifrices and observed that those with low $\mathrm{pH}$ were more abrasive. However,
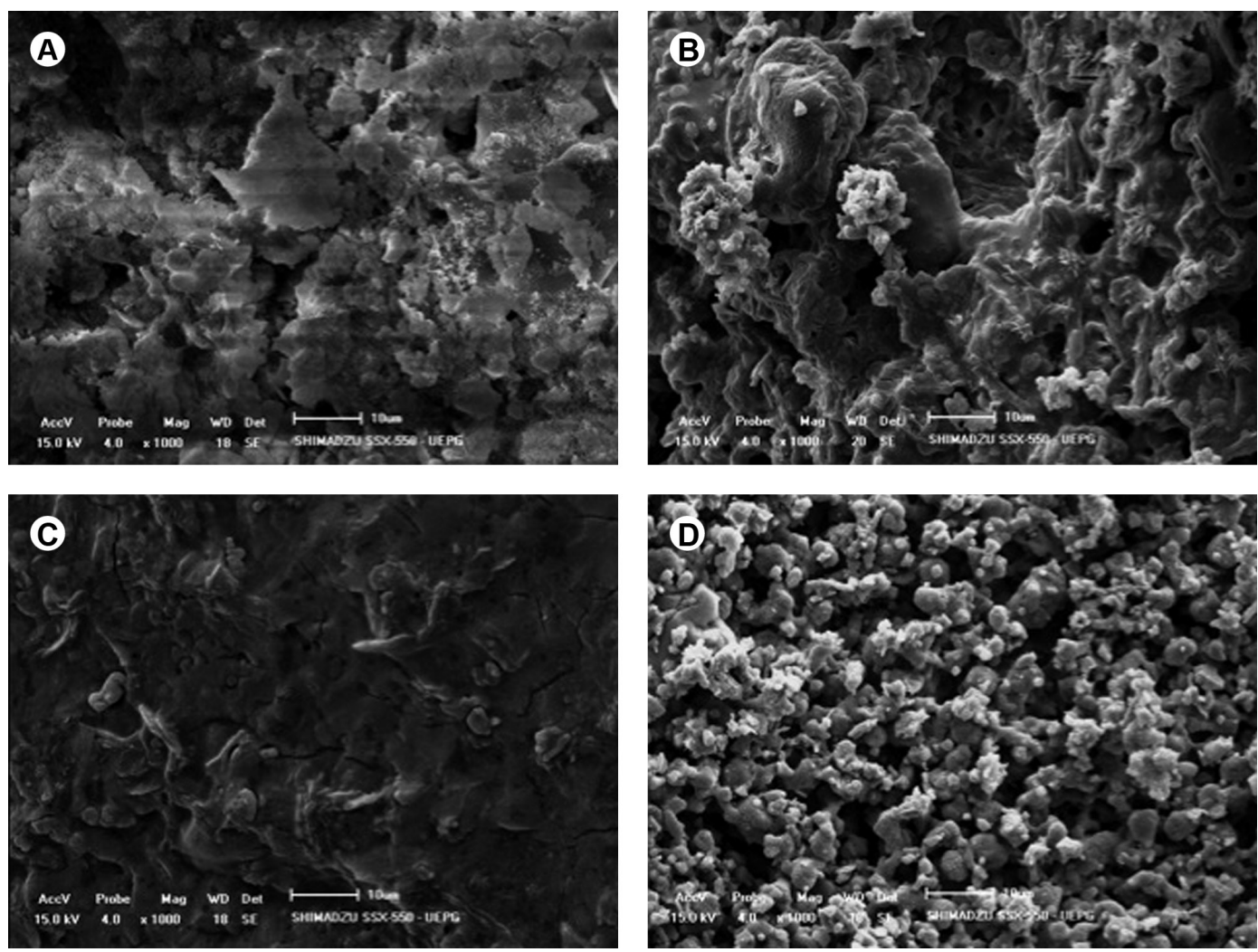

Figure 3. Dentifrices containing whitening agents: SEM micrographs of inorganic particles. A: Close-Up Whitening; B: Colgate Sensitive Branqueador; C: Sensodyne Branqueador; D: Sorriso Branqueador. 
when treating a patient with dentin exposure, acidic $\mathrm{pH}$ dentifrice may have negative effects on this surface, leading to the loss of dentine structure. Therefore, patients with this condition need to be advised to use dentifrices with neutral or basic $\mathrm{pH}$. In a previous study (13), when a slurry with basic $\mathrm{pH}$ was used after softening, a slightly better rehardening could be measured (13). It is believed that the manufacturers are concerned about formulating dentifrices with higher $\mathrm{pH}$ to eliminate the possibility of low $\mathrm{pH}$ aggravating dental structure loss by abrasion (9).

In order to understand the greater variation in abrasiveness of different trademarks, the desiccation loss of dentifrices was also investigated. The desiccation loss in the present study was similar among the groups. Sensodyne Original (64.07\%), Sensodyne Cool Gel (60.85\%) and Sensodyne Branqueador (65.83\%) showed greater content of abrasive agents, but other studies found no correlation between the content of abrasives and abrasion degree $(15,16)$.

The dentifrice stain-removal property is basically related to the abrasives in its composition. It is important to point out that if, on the one hand, increased dentifrice abrasiveness leads to improved stain removal efficacy, on the other hand, it increases tooth wear (16).

The quality and quantity of abrasives of dentifrices may influence its abrasiveness. The most common abrasive agents present in dentifrices are: calcium carbonate and silica, although others remain present. Larger content of abrasives may harm hard tissues, soft tissues and dental restoration. The most common harms are: gingival recession and cervical abrasion, both usually associated with dentin hypersensitivity $(13,17)$.

In the present study, silica and calcium carbonate were observed as abrasive agents and some of dentifrices present both of them. Most dentifrices containing silica had smaller particles with regular shape as shown in Figures 1-3. In the study carried out by Vicentini et al. (9), the silica dentifrices presented the least abrasive power. In an in situ study, Pickles et al. (18) observed that a commercial silica dentifrice caused less dentine wear tooth when compared with other dentifrices containing calcium carbonate, but this wear was not significantly different. Considering dentin surface, calcium carbonate has shown low abrasion, which probably reflects the softness of this material in relation to the other abrasives in dentine (5). A previous study concluded that dentifrices with calcium carbonate of rhombohedral or ovoid shape, a more regular structure, present lower abrasiveness than more irregular particles (12). Another study showed that dentifrices with sharp particles, regardless of the abrasive agent, calcium carbonate or silica abrasives, present lower abrasiveness (15). It is important to remind that chemically identical abrasives may have different effects and the mixture of these abrasives may result in effects that differ from those when the components are used individually (9). The package and tubes of dentifrices only indicates the main type of abrasive contained in the formula, but the shape and size of particles are not mentioned. It reinforces the need of further studies on the dentifrice abrasiveness so that dentists may recommend the best one for each patient's specific need (13).

Particle size and shape are also found to influence abrasion, particularly when comparing abrasives made from the same compound, as silicon dioxide (artificial silica) (15). This study presented some dentifrices with irregular and large particles, demonstrating greater abrasiveness. Sensodyne Cool Gel, Close Up Gel, Close Up Whitening showed greater and more irregular particles, a feature that may indicates a high capacity of abrasion. Therefore, Sensodyne Cool Gel showed acid $\mathrm{pH}$ and a greater content of abrasives $(60.85 \%)$, features that may turn these dentifrices not recommended for patients with gingival recession.

A dentifrice to be recommended should follow an individual evaluation of each patient's need (19). However, it seems to be more reasonable that people should use less abrasive dentifrices (13).

This study addressed some features of dentifrices, which is an important step for recommending the ideal dentifrice for each patient considering the individual oral condition. Low $\mathrm{pH}$, high desiccation loss and solid residue analysis, in addition to irregular and large particles are important characteristics to assume a more abrasive capacity of a dentifrice. However, if one considers a patient with high caries activity, the indication of an acidic dentifrice is valid as a source of fluoride to bind on tooth surface. Considering the results presented in this study, the next step is to evaluate dentifrices with different characteristics on tooth surface (enamel and dentin) and their abrasive capacity under clinical conditions on toothbrushing.

\section{Resumo}

Dentifrícios com diferentes composições estão disponíveis no mercado, mas existe pouca informação sobre suas propriedades. 0 objetivo do presente estudo "in vitro" foi avaliar as características físico-químicas de 12 dentifrícios divididos em 3 categorias, como contendo: agentes dessensibilizantes, triclosan ou agentes clareadores. Perda por dessecação/ análise de resíduos: $5 \mathrm{~g}$ do dentifrício foi pesado cinco vezes para cada grupo. Análise do $\mathrm{pH}$ : foram diluídos $5 \mathrm{~g}$ do dentifrício suspensos em três partes de água destilada e analisados usando um potenciômetro digital. Microscopia eletrônica de varredura (MEV): análise das cinzas, forma e tamanho de partículas dos agentes abrasivos. Espectroscopia de raios X por dispersão em energia (EDX): identificação dos elementos abrasivos. Análise dos dados: Os dados foram analisados usando ANOVA e teste pos-hoc Bonferroni $(\alpha=0,05)$. Perda por dessecação: $38,21 \%$ à $65,83 \%$. Os dentifrícios contendo triclosan e agentes dessensibilizantes mostraram diferença significante entre eles $(p<0,05)$. Dentifricios clareadores mostraram diferença significante entre Close-Up Whitening e Sensodyne Branqueador (44,72\% e 65,83\%, respectivamente). A maioria 
dos dentifrícios apresentaram $\mathrm{pH}$ básico ou neutro. Diferentes formas e tamanhos das partículas foram observadas na análise em MEV. Elementos abrasivos foram identificados no EDX. Estes resultados demonstram que os dentifrícios avaliados a presentaram diferentes propriedades e que suas composições influenciam diretamente em características, resultando em ações mais ou menos abrasivas sobre a superficie do dente. 0 conhecimento sobre as caracteristicas dos dentifricios é importante para indicar o produto ideal para cada caso.

\section{Acknowledgements}

The authors thank the Brazilian research funding agency CAPES for the financial support.

\section{References}

1. Kodaka T, Kuroiwa M, Okumura J, Mori R, Hirasawa S, Kobori M. Effects of brushing with a dentifrice for sensitive teeth on tubule occlusion and abrasion of dentin. J Electron Microsc 2001;50:57-64.

2. White DJ, Kozak KM, Gibb R, Dunavent J, Klukowska M, Sagel PA. A 24-hour dental plaque prevention study with a stannous fluoride dentifrice containing hexametaphosphate. J Contemp Dent Pract 2006;7:1-11.

3. De Menezes M, Turssi CP, Hara AT, Messias DC, Serra MC. Abrasion of eroded root dentine brushed with different toothpastes. Clin Oral Investig 2004;8:151-155.

4. Hooper S, West NX, Pickles MJ, Joiner A, Newcombe RG, Addy M. Investigation of erosion and abrasion on enamel and dentine: a model in situ using toothpastes of different abrasivity. J Clin Periodontol 2003;30:802-808.

5. Moore C, Addy M. Wear of dentine in vitro by toothpaste abrasives and detergents alone and combined. J Clin Periodontol 2005;32:12421246.

6. Worschech CC, Rodrigues JA, Martins LR, Ambrosano GM. Brushing effect of abrasive dentifrices during at-home bleaching with 10\% carbamide peroxide on enamel surface roughness. J Contemp Dent Pract 2006:7:25-34.
7. Brighenti FL, Delbem AC, Buzalaf MA, Oliveira FA, Ribeiro DB, Sassaki KT. In vitro evaluation of acidified toothpastes with low fluoride content. Caries Res 2006;40:239-244.

8. Kielbassa AM, Gillmann L, Zantner C, Meyer-Lueckel H, Hellwig $E_{\text {, }}$ Schulte-Monting J. Profilometric and microradiographic studies on the effects of toothpaste and acidic gel abrasivity on sound and demineralized bovine dental enamel. Caries Res 2005;39:380-386.

9. Vicentini $B C, B r a g a S R$, Sobral MA. The measurement in vitro of dentine abrasion by toothpastes. Int Dent J 2007;57:314-318.

10. Alves KM, Pessan JP, Brighenti FL, Franco KS, Oliveira FA, Buzalaf MA, et al.. In vitro evaluation of the effectiveness of acidic fluoride dentifrices. Caries Res 2007;41:263-267.

11. Hove LH, Stenhagen KR, Holme B, Tveit AB. The protective effect of SnF containing toothpastes and solution on enamel surfaces subjected to erosion and abrasion in situ. Eur Arch Paediatr Dent 2014 [Epub ahead of print. DOI: 10.1007/s40368-013-0107-7].

12. Benzian $H$, Holmgren $C$, van Loveren $C$, van Palenstein Helderman $W$. Analysing the amount of soluble fluoride in toothpastes. Oral Health Prev Dent 2013;11:300.

13. Lussi $A$, Megert $B$, Eggenberger $D$, Jaeggi T. Impact of different toothpastes on the prevention of erosion. Caries Res 2008;42:62-67.

14. Johannsen $G$, Tellefsen $G$, Johannsen A, Liljeborg A. The importance of measuring toothpaste abrasivity in both a quantitative and qualitative way. Acta Odontol Scand 2013;71:508-517.

15. Pascaretti-Grizon F, Mabilleau G, Chappard D. Abrasion of 6 dentifrices measured by vertical scanning interference microscopy. J Appl Oral Sci 2013;21:475-481.

16. Davis WB, Winter PJ. Measurement in vitro of enamel abrasion by dentifrice. J Dent Res 1976;55:970-975.

17. Ashmore $\mathrm{H}$, Van Abbe NJ, Wilson SJ. The measurement in vitro of dentine abrasion by toothpaste. Br Dent J 1972;133:60-66.

18. Pickles MJ. Tooth wear. Monogr Oral Sci 2006;19:86-104.

19. Peros K, Mestrovic S, Anic-Milosevic S, Rosin-Grget K, Slaj M. Antimicrobial effect of different brushing frequencies with fluoride toothpaste on Streptococcus mutans and Lactobacillus species in children with fixed orthodontic appliances. Korean J Orthod 2012:42:263-269. 